\title{
Reconfiguration of a climbing robot in an all-terrain hexapod robot
}

\author{
Lisbeth Mena ${ }^{1}$, Héctor Montes ${ }^{1,2}$, Roemi Fernández ${ }^{1}$, Javier Sarria ${ }^{1}$, \\ and Manuel Armada ${ }^{1}$ \\ ${ }^{1}$ Centro de Automática y Robótica CSIC-UPM \\ Ctra. Campo Real Km 0.220, Arganda del Rey, 28020 Madrid, Spain \\ hector.montesacsic.es \\ ${ }^{2}$ Facultad de Ingeniería Eléctrica, Universidad Tecnológica de Panamá \\ Via UTP, Panama City, Panama
}

\begin{abstract}
This work presents the reconfiguration from a previous climbing robot to an all-terrain robot for applications in outdoor environments. The original robot is a six-legged climbing robot for high payloads. This robot has used special electromagnetic feet in order to support itself on vertical ferromagnetic walls to carry out specific tasks. The reconfigured all-terrain hexapod robot will be able to perform different applications on the ground, for example, as inspection platform for humanitarian demining tasks. In this case, the reconfigured hexapod robot will load a scanning manipulator arm with a specific metal detector as end-effector. With the implementation of the scanning manipulator on the hexapod robot, several tasks about search and localisation of antipersonnel mines would be carried out. The robot legs have a SCARA configuration, which allows low energy consumption when the robot performs trajectories on a quasi-flat terrain.
\end{abstract}

Keywords: Hexapod robot, walking and climbing robot, SCARA configuration, antipersonnel landmines, control architecture.

\section{Introduction}

Locomotion of legged robots has been of great interest by many research groups, for several decades, with the objective to reproduce movements carried out by animals when they move. A historical perspective of walking robot technology can be found in the literature, for example in [1-3], among other. In these references, the evolution of the legged robots, besides other concepts, are described. On the other hand, the development of new technologies has allowed the design and construction of an innovative generation of legged robots (climbing and walking) in the last decade, e.g., TriAthlete Rover developed by Jet Propulsion Lab [4], the RiSE, the BigDog, the LittleDog, the LS3 and the Cheetah [5-9] developed by Boston Dynamics in cooperation with other institutions, and partially funded by DARPA. 
In just over two decades the Centre for Automation of Robotics - CAR (CSICUPM) has designed and developed some kinds of legged robots (climbing and walking robots) for several applications. Examples of some of them are TRACMINER, RIMHO, RIMHO2, ROWER, REST, REST-II, SILO4, SILO2, SILO1, SILO6, ROBOCLIMBER [2, 10-19], which have been used as robot prototypes (with one, two, four and six legs) from educational purposes until carrying out consolidation works of rocky mountainsides.

Firstly, in this paper, it is presented a brief description of the previous climbing robot, whose name is REST (from the acronym in Spanish: Robot Escalador de Soldadura a Tope) [13, 20]. This brief description consists of the explanation of the main parts of the robot, focusing in the subsystems that have been reconfigured.

Secondly, the modifications carried out in some parts/subsystems of the climbing robot to convert it in a walking robot will be presented. Fundamentally, the modifications were carried out in the feet, in the electronics, in the power supply, the rear control panel, the wireless communication, and, evidently, in the design of the control algorithms.

The general description of the all-terrain hexapod robot will be presented, taking into account the leg configuration, the subsystems that form the hexapod robot, the working area of the leg, and its control architecture.

Finally, in this article some experimental results are shown when the hexapod robot executes a gait to carry out a task established. In this case, currently, the hexapod walking robot performs gaits for humanitarian demining tasks. However, this walking machine could be prepared to complete other kind of works in indoor and outdoor environments, according its size and versatility.

\section{Brief description of the previous climbing robot}

REST climbing hexapod robot was designed with the purpose to move high payloads on vertical ferromagnetic surface. The main areas of applications of this robot comprise inspection, maintenance, and intervention tasks in industrial environment. Specifically, the REST could perform autonomous welding tasks on steel sheets used in hulls of civil ships [13, 20].

SCARA configuration is used in the legs of the REST, constructed with a hard structure of aluminum 7075, in order to avoid deformations when the robot climbs on a vertical surface. Each leg has three degree of freedom (DOF), two rotational, and one prismatic. In the last DOF (prismatic), it is installed the electromagnetic foot.

The electromagnetics feet can be compared with grasping's devices due to the feet must be "gripped" to the ferromagnetic surface, to move on the vertical surface. The electromagnetic foot consists of an array of eight special electromagnets (permanent magnets + electromagnets), which are attached to the wall by default (without electric energy), and unattached when the electric current is applied. This guarantees the robot does not fall down when the electric power supply is cut, unexpectedly.

Fig. 1(a) shows the REST climbing hexapod robot on a ferromagnetic surface with the power cord attached at the front of its body, and a steel rope connected between 
the robot body and a fixed point in the upper part of the wall, for security purpose. For more details of this robot please refer to [13, 20].

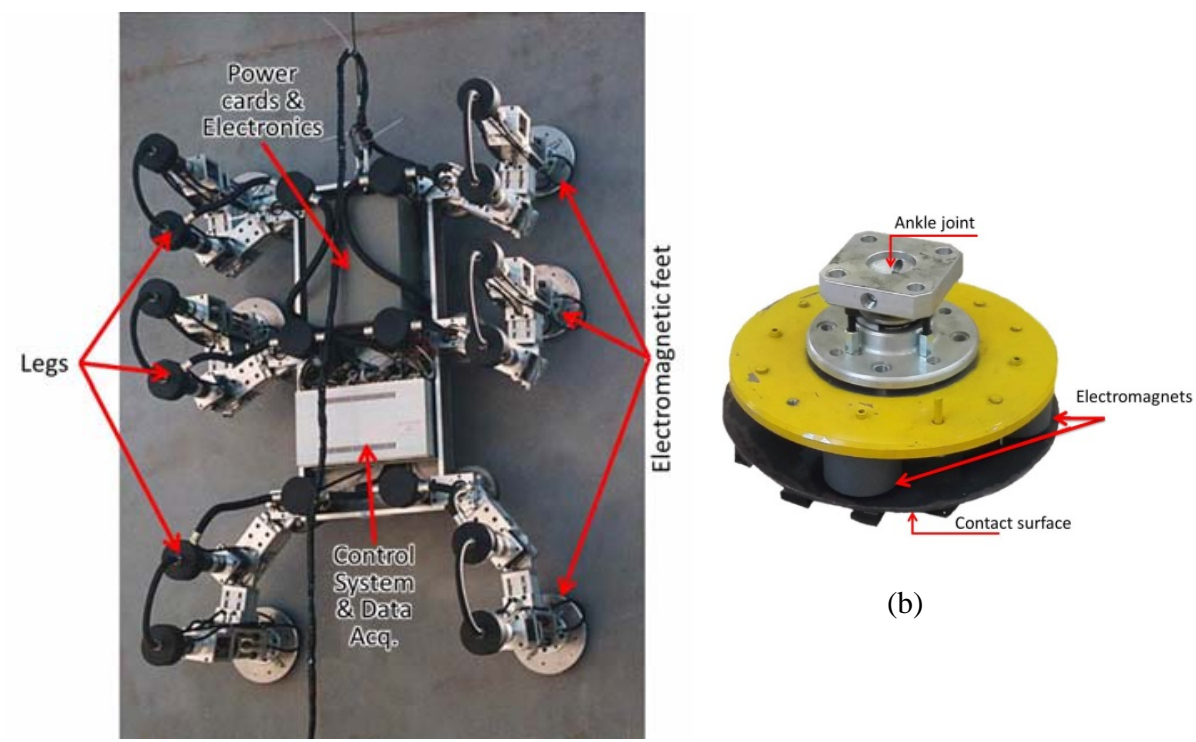

(a)

Fig. 1. (a) REST climbing robot on a ferromagnetic surface; (b) Electromagnetic foot of the REST.

\section{Reconfiguration of the climbing robot in a walking robot}

It is evident that one of the first modifications realised in the climbing robot to convert it to a walking robot must be the new design of the feet. However, some details must be considered in the realization of this design, how much load must support each foot depending the terrain where the robot moves, must be considered rotational passive joint to avoid some inaccuracy in the positioning of the robot legs, is it necessary a position sensor in order to know when the foot contacts with the terrain, and force sensors, etc.

In addition, to the modifications on the robot feet, other changes or inclusion of new subsystems were carried out. Some modifications or other add-on have been realized/installed in the robot, for example, in the electronics, in the power supply, in the rear control panel on the robot, the wireless communications, and in the control algorithms.

The new design of each foot consists of the some parts, one of them is the internal axis of the foot (of steel plated with nickel) ending in a nylon cone. This foot supports loads up to $2000 \mathrm{~kg}$, which it is important for the new reconfigured robot. The internal axis of the foot must move inside the other parts that form the foot, in order to activate the inductive proximity sensor installed in the up part of the foot. This indicates that the foot has made contact with the terrain. With the use of a spring the axis of the 
foot returns to the original position, in this case the proximity sensor send to the control system an off signal. Fig. 2 depicts the schematic diagram and one picture of the new foot installed on the walking robot.

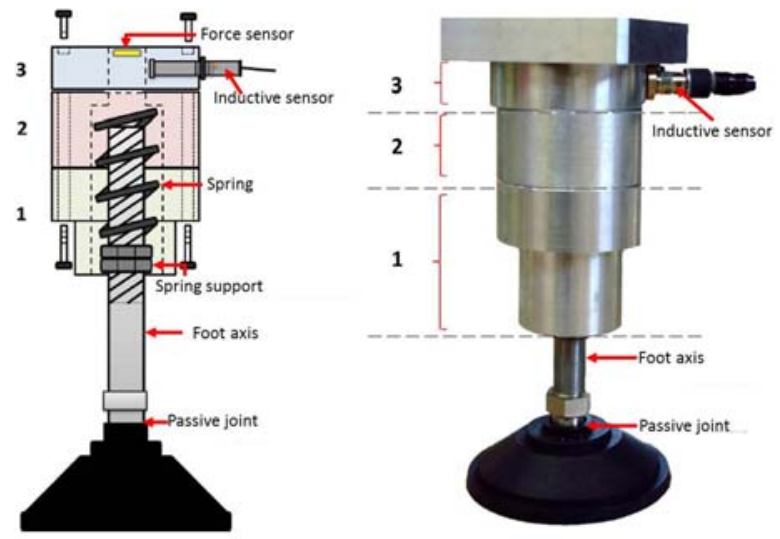

Fig. 2. Schematic diagram (to the left) and a picture (to the right) of the new foot designed for the all-terrain walking robot.

The previous robot had a tethered cable, which supplied of electric energy to the robot, and Ethernet connection between on-board computer and an external computer. This tethered cable was eliminated in order to provide autonomy to the new reconfigured robot. The power supply was replaced by two batteries of 12 VDC connected in series and two DC-DC converters with the power and characteristics required for the control stage and the power stage of the system. On the other hand, the communication between the on-board PC and the remote PC has been realized by mean of a wireless connection. Two types of standard wireless connections have been installed in the robot. One of them is a wireless connection using the local area network (LAN) of any institution where the robot is working. The other wireless connection is a pointto-point connection between the on-board computer and a remote portable computer. In Fig. 3 the two wireless connections implemented in the reconfigured robot are shown.

The first option is very useful in laboratory and in indoor environments (see Fig. 3(a)), since it is easy connection. However, in other environment where LAN connections are impossible that exist (e.g., at some external environment as land infested by antipersonnel landmines), then this option is not useful. On the other hand, the second option of wireless communications will facilitate the connection between the robot and remote PCs in outdoor environments, where not exists a local network provider. In this case a point-to-point network is configured by directly connecting the access point to one or more remote computers, assigning them fixed IPs addresses (see Fig. 3(b)). Off-the-shelf devices are used in both standard wireless communications, which will depend on the bandwidth required for the tasks that will be carried out in different applications. 


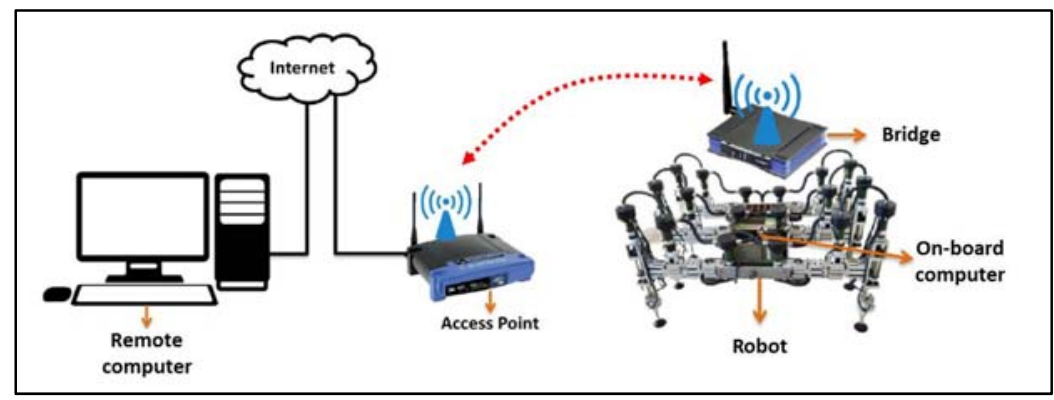

(a)

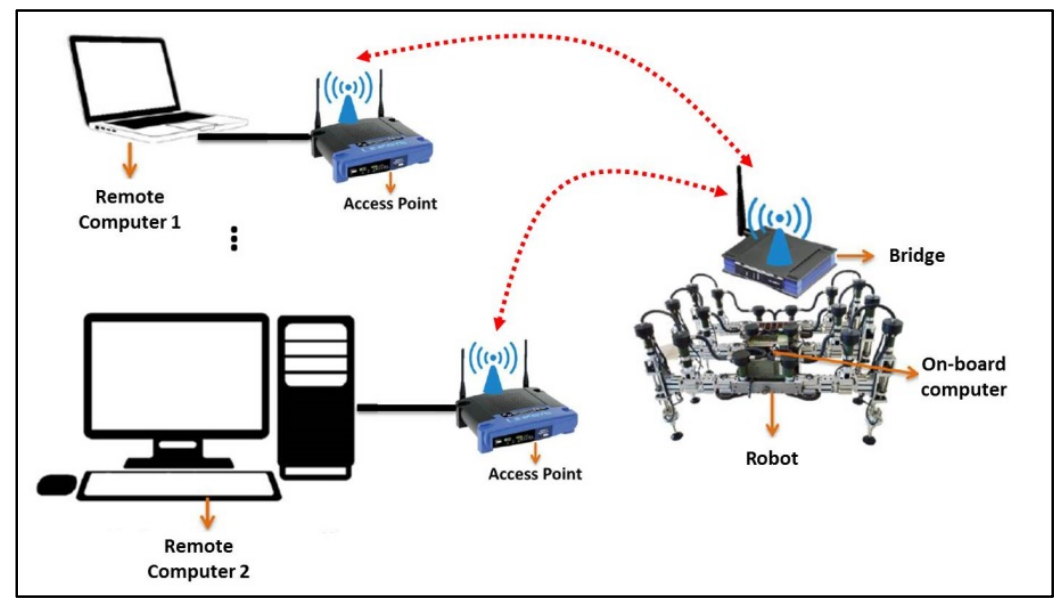

(b)

Fig. 3. Wireless communication between the robot and the remote computer. (a) Communication through the LAN; (b) Communication through point-to-point connection.

\section{Description of the all-terrain hexapod robot}

The all-terrain hexapod robot has six legs in SCARA configuration of 3 DOF each one. The first two joints, the shoulder and the elbow, are rotational and the third joint, where the foot is implemented, is prismatic. Each leg has five inductive proximity sensors in order to initialize each leg and subsequently to verify the position of the leg during the locomotion process, besides to detect the contact between the feet with the soil. Fig. 4 shows the configuration of one of the legs.

The four external legs installed on the robot have similar working areas among them, but are different that the working area of the legs assembled in the middle of the robot. All working areas of the legs are restricted by the body robot and the collocation of the respective adjacent legs. Fig. 5 shows the working area of the external legs of the robot. In the figure it is possible to see the three joints $\left(q_{1}, q_{2}\right.$ and $\left.q_{3}\right)$ and the top view (left) and frontal view (right) of the working area of the leg. 


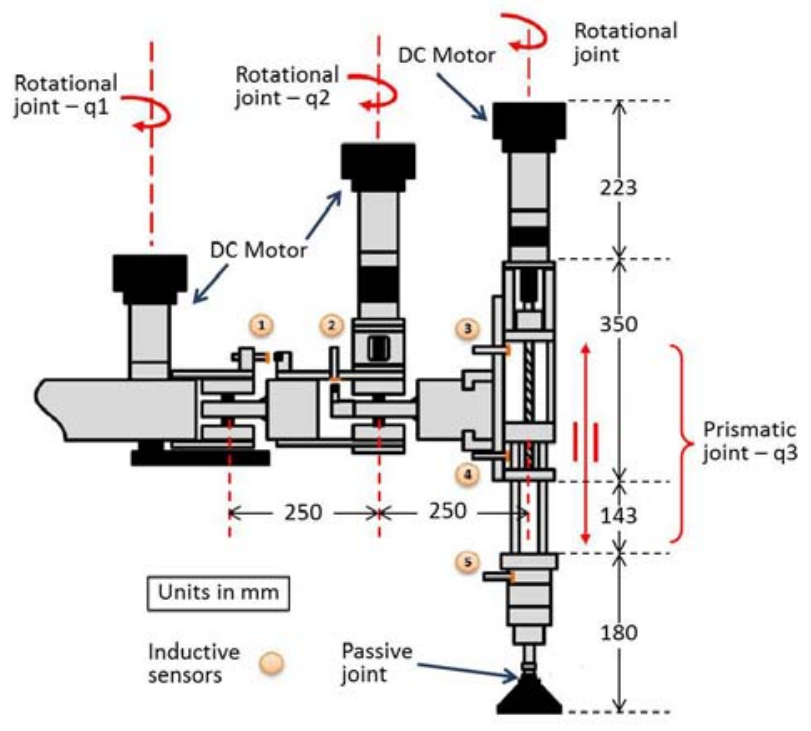

Fig. 4. Configuration of the leg.

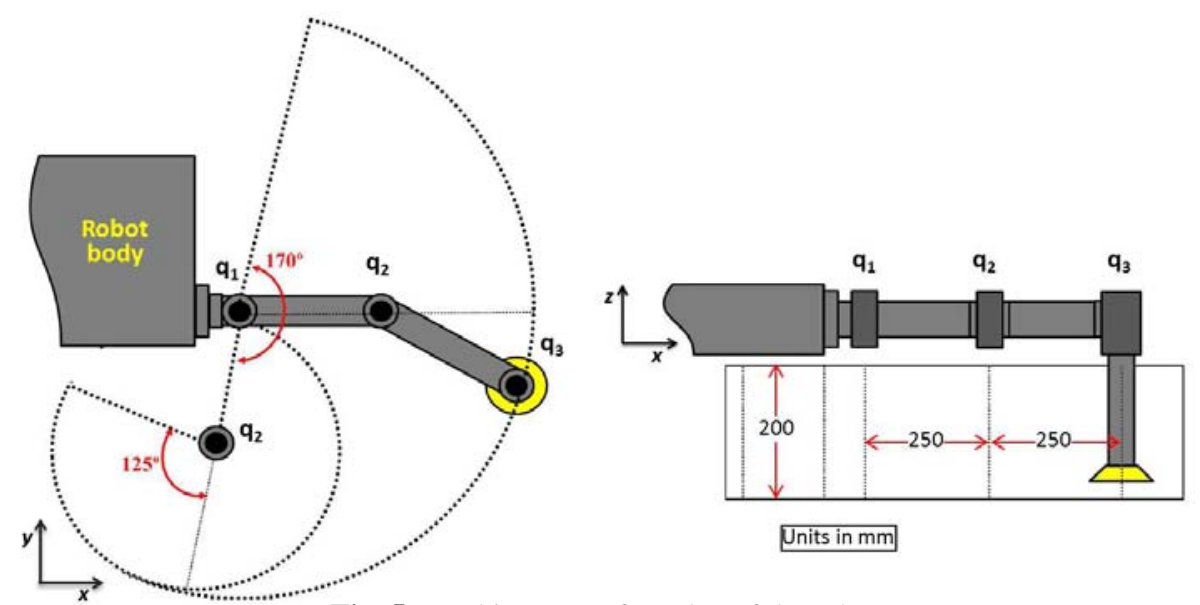

Fig. 5. Working area of one leg of the robot.

The system architecture of this all-terrain robot consist of an on-board computer, control cards, data acquisition boards, power cards, signals conditioner cards, positioning sensors, DC motors, Wi-Fi communication system, DGPS, batteries, and other devices and accessories. This system architecture provides a reliable starting point for developing several control strategies in order to carry out several tasks in outdoor environment, e.g. in humanitarian demining tasks [21-22]. Fig. 6 shows the main subsystems implemented in the hexapod robot. 


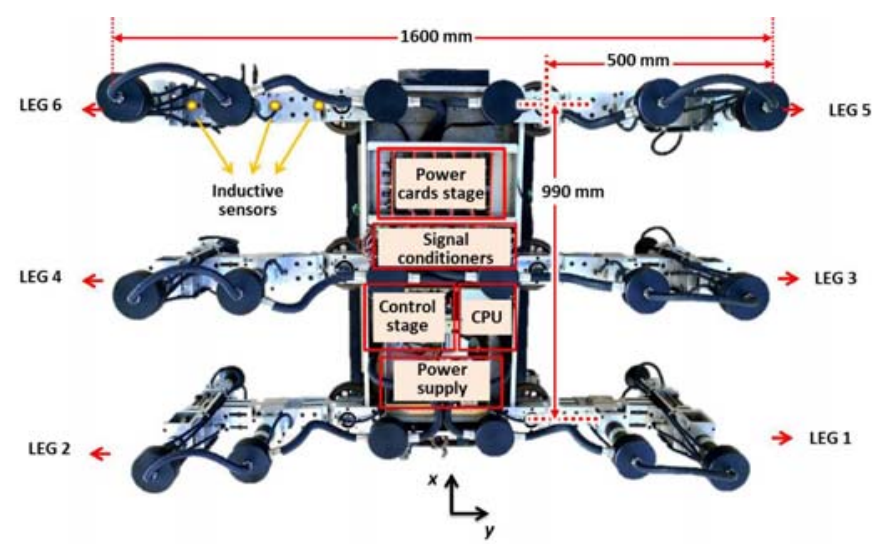

Fig. 6. Top view of the hexapod robot with its main subsystems.

This walking robot is able to load different tools on-board in order to carry out several tasks in outdoor environment. Up to $300 \mathrm{~kg}$ of mass can to support this robot, for this reason it could perform several kind of works. One example is carry out stable locomotion in order that a scanning manipulator arm can perform suitable movements of its end effector, where is installed the metal detector head, in humanitarian demining applications [21-22]. Fig. 7 shows the general control architecture of the hexapod robot.

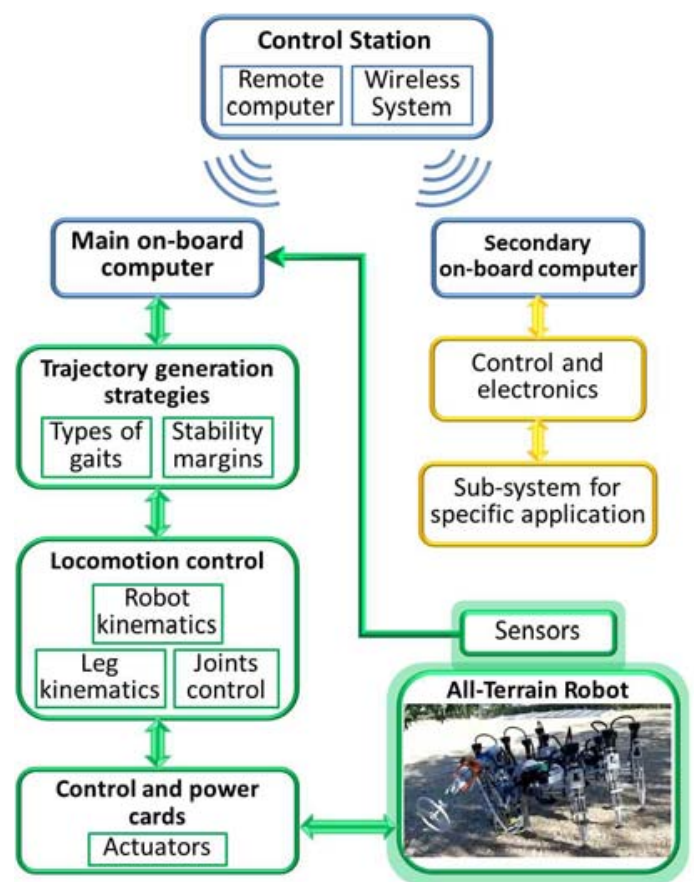

Fig. 7. General control architecture of the hexapod robot. 
The general control architecture shown in Fig. 7 presents the main parts implemented in the all-terrain hexapod robot, and other stages that may have the tools installed over this robot in order to perform specific tasks. The communication between the base station computer and the on-board computer is by means of Wi-Fi. High level instructions are only sent by the remote computer, besides through this computer the teleoperation tasks could be carried out. The locomotion control of the robot with different gaits is performed with the control of on-board computer. On the other hand, a secondary on-board computer can be installed on the hexapod robot, if an external tool is installed and if required by this external system. Other control and electronics card must be installed in order to drive the external tool. One example of an external tool would be a scanning manipulator arm to detect and localize antipersonnel mines [21-22].

\section{$5 \quad$ Experimental results}

Several experimental tests in indoor and outdoor environment with different locomotion patterns have been carried out with the reconfigured all-terrain hexapod robot. This robot has demonstrated high stability during the execution of several trajectories. It has been able to move extra loads installed at the body front during some locomotion tests, and the additional power consumption has been insignificant with respect to the execution of gait patterns without extra payload. Consequently, it will be feasible to load on-board different tools and other additional sensors, without to contribute to significant energy consumption.

Fig. 8 shows some experimental results during the execution of a discontinuous gait using the alternating tripod mode. In this case only the Cartesian positions of the leg 1 of the robot are shown. Only two steps are presented in Fig. 8 in order to see, in best way, the details of the experimental results.



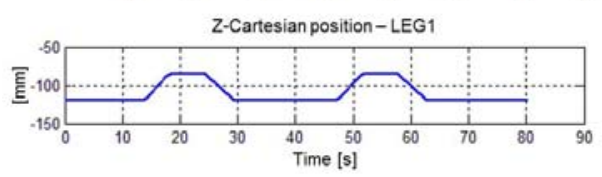

(a)

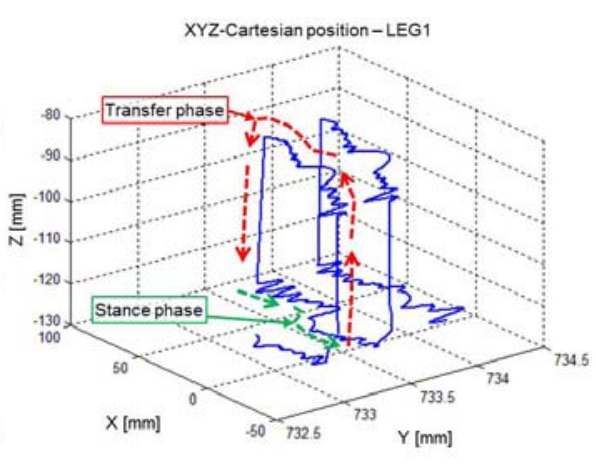

(b)

Fig. 8. Some experimental results during performing of an alternating tripod discontinuous gait. (a) Cartesian position of Leg 1; (b) Phases of transfer and stance of leg 1. 
The Y-axis drift of the leg 1 position is appreciated (see Fig. 8(a)). However, this drift is about $1 \mathrm{~mm}$ in two steps, therefore, it can be corrected easily. This minor deviation is due to some backlashes there are in the leg joints. In Fig. 8(b) the transfer and stance phase of the leg 1 during two steps are shown. The vibrations observed in Yaxis, besides, are related with the intrinsic forces in the robot structure when the machine moves-forward its body.
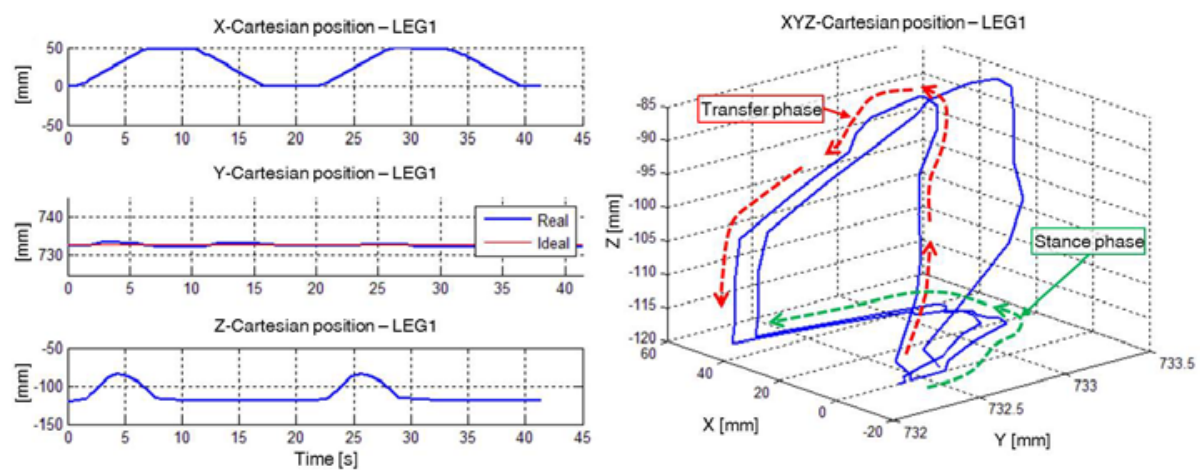

Fig. 9. Some experimental results during performing of an alternating tripod continuous gait.

(a) Cartesian position of Leg 1; (b) Phases of transfer and stance of leg 1.

Fig. 9 shows some experimental results during the execution of a continuous gait using the alternating tripod mode. As in the previous figure only the positions of the leg 1 are shown. The other leg positions that form the same tripod are similar. Evidently, each tripod has a phase of $180^{\circ}$ respect to each other. In this mode the transfer and stance phase are carried out suitable way considering the experimental results presented in Fig. 8. The backlashes problems diminish when the hexapod robot executes a continuous gait. This is because during continuous forward-motion of the robot the backlashes are compensated.

Fig. 10 shows a photographic sequence of a specific trajectory followed by the allterrain hexapod robot in outdoor environment. Several steps were carried out by the robot, which loads a scanning manipulator arm installed in front of the robot. During this test the manipulator was not used. However, the hexapod robot and the scanning manipulator are used to carry out detection and localization tasks of antipersonnel landmines in order to humanitarian demining applications. 


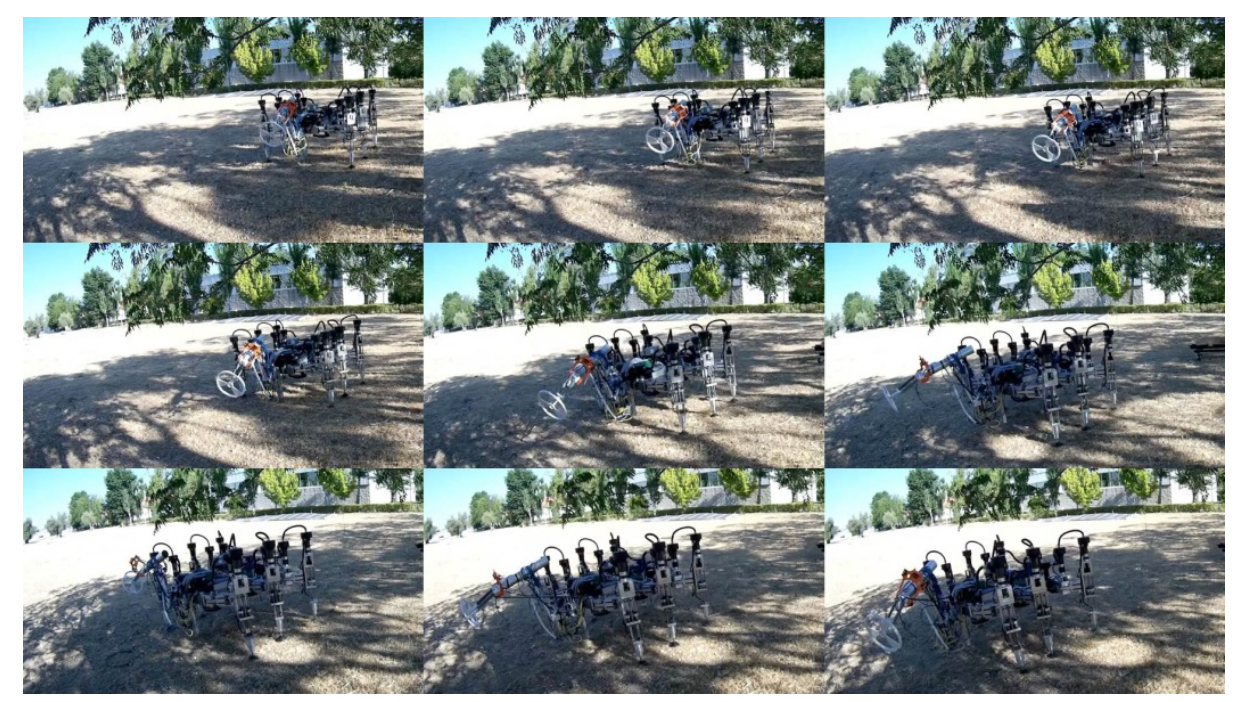

Fig. 10. Photographic sequence (left to right and up to down) of a gait pattern of the all-terrain hexapod robot.

\section{Conclusions}

This work presented some details of the reconfiguration of a climbing robot named REST in an all-terrain hexapod robot. This walking robot must be able to carry out different kind of works in external environment. However, this machine could perform several tasks in indoor environments, too. One example is to perform specific trajectories with a scanning manipulator loaded on its structure in order to perform humanitarian demining tasks.

Since this all-terrain hexapod robot can sustain high payloads (up to $300 \mathrm{~kg}$ ), it could carry out several kinds of tasks, with a good stability, bearing different tools/sensors installed on it. These characteristics will be very important to carry out future projects for different types of applications. Therefore, the reconfiguration made to the original climbing robot to an all-terrain walking robot has been successful. Future works with this hexapod robot will show important results related with the energy saving, while the robot performs several gaits with different loads.

\section{Acknowledgments}

The authors acknowledge funding of this work under TIRAMISU Project - Grant Agreement $\mathrm{N}^{\circ} 284747$ of the 7FP, and partial funding from the RoboCity2030-III-CM project (Robótica aplicada a la mejora de la calidad de vida de los ciudadanos. Fase III; S2013/MIT-2748), funded by Programas de Actividades I+D en la Comunidad de 
Madrid and cofunded by Structural Funds of the EU. Dr. Héctor Montes also acknowledges support from Universidad Tecnológica de Panamá.

\section{References}

1. Bekey, G.A.: Autonomous Robots: From Biological Inspiration to Implementation and Control. MIT Press. USA (2005)

2. Gonzalez de Santos, P., Garcia, E., Estremera, J.: Quadrupedal locomotion: an introduction to the control of four-legged robots. Springer, Verlag. Germany (2006)

3. Tenreiro, J.A., Silva, M.: An overview of legged robots. In: Proc. International Symposium on Mathematical Methods in Engineering, Ankara, Turkey (2006)

4. Heverly, M., Matthews, J., Frost, M., Quin, C.: Development of the Tri-ATHLETE Lunar Vehicle Prototype, Proceedings of the 40th Aerospace Mechanisms Symposium, NASA, May 12, 2010.

5. Saunders, A., Goldman, D.I., Full, R.J., Buehler, M.: The RiSE Climbing Robot: Body and Leg Design. Unmanned Systems Technology VIII, Proc. of SPIE, 6230(17), 1-13 (2006)

6. Raibert, M., Blankespoor, K., Nelson, G., Playter, R., the BigDog Team: BigDog, the Rough-Terrain Quaduped Robot. In: Proc. The IFAC Workshop on Navigation, Guidance and Control of Underwater Vehicles, IFAC NGCUV 2008, Killaloe, Ireland, April 8-10, 2008.

7. Boston Dynamics: LittleDog Robot 1.0 User Guide. Cambridge, MA, pp. 64 (2006)

8. Mandelbaum, R.: Legged Squad Support System, Industry Day. DARPA (2008)

9. Massachusetts Institute of Technology: Run, cheetah, run: New algorithm enables cheetah robot to run and jump, untethered, across grass. ScienceDaily, 15 September 2014. Available in: www.sciencedaily.com/releases/2014/09/140915114524.htm

10. Gonzalez de Santos,P., Armada, M., García, E., Akinfiev, T., No, J., Prieto, M., Nabulsi, S., Cobano, J. A., Ponticelli, R., Sarria, J., Reviejo, J., Salinas, C. y Ramos, A.: Desarrollo de robots caminantes y escaladores en el IAI-CSIC, Departamento de Control Automático Instituto de Automática Industrial - CSIC, Congreso Español de Informatica - CEDI, (2007).

11. Gonzalez de Santos, P., and Jimenez, M. A.: Generation of Discontinuous Gaits for Quadruped Walking Machines. Journal of Robotic Systems, 12(9), 599-611(1995)

12. Gonzalez de Santos, P., Armada, M.A., Jimenez, M.A.: Ship building with ROWER. IEEE Robotics and Automation Magazine, 7(4), 35-43 (2000)

13. Grieco, J.C., Prieto, M., Armada, M., Gonzalez de Santos, P.: A Six-legged Climbing Robot for high Payloads. In: Proc. 1988 IEEE International Conf. on Control Applications, pp. 446-450. Trieste, Italy (1998)

14. Gonzalez de Santos, P., Garcia, E., Estremera, J. and Armada, M.A.: DYLEMA: Using walking robots for landmine detection and location. The International Journal of System Science, 36(9), 545-558 (2005)

15. Montes, H.: Análisis, diseño y evaluación de estrategias de control de fuerza en robots caminantes. PhD Thesis, Universidad Complutense de Madrid (2005)

16. Akinfiev, T., Armada, M., Montes, H.: Vertical Movement of Resonance Hopping Robot with Electric Drive and Simple Control System. In: Proc. of IEEE, $11^{\text {th }}$ Mediterranean Conference on Control and Automation MED’03, Rhodes, Greece (2003)

17. Armada, M., Caballero, R., Akinfiev, T., Montes, H., Manzano, C., Pedraza, L., Ros, S., González de Santos, P.: Design of SILO2 Humanoid Robot. In: Proc. of The third IARP 
International Workshop on Humanoid and Human Friendly Robotics, pp. 37-42. Tsukuba, Ibaraki, Japan (2002)

18. Nabulsi, S., Montes, H., Armada, M.: ROBOCLIMBER: Control System architecture. In: Proc. Int. Conf. of Climbing and Walking Robots, CLAWAR 2004, pp. 943-952. Madrid, Spain (2004)

19. Nabulsi, S., Sarria, J., Montes, H., Armada, M.: High Resolution Indirect Feet-Ground Interactions Measurement for Hydraulic Legged Robots. IEEE Transactions on Instrumentation and Measurement, 58(10), 3396-3404 (2009)

20. Grieco, J.C.: Robots Escaladores. Condiciones de Diseño, estabilidad y Estrategias de Control. PhD Thesis, Universidad de Valladolid (1997)

21. Montes, H., Mena, L., Fernández, R., Sarria, J., González de Santos, P., Armada, M.: Hexapod Robot for Humanitarian Demining. In: Proc. RISE 2015, 8th IARP Workshop on Robotics for Risky Environments [CD], 28-29 January 2015, Naval Academy, Lisbon, Portugal (2015)

22. Montes, H., Mena, L., Fernández, R., Sarria, J., Armada, M.: Inspection Platform for Applications in Humanitarian Demining. 18th International Conference on Climbing and Walking Robots and the Support Technologies for Mobile Machines. Assistive Robotics: pp.446-453, 6-9 September HangZhou, China (2015) 